\title{
Solvent Quality-mediated Regioselective Modification of Gold Nanorods with Thiol-terminated
}

\section{Polymers}

Fan Li, ${ }^{\S}$ Ke Wang, ${ }^{\S}$ Zhengping Tan, Chen Guo, Yuanyuan Liu, Haiying Tan, Lianbin Zhang, * Jintao Zhu*

State Key Laboratory of Materials Processing and Die \& Mould Technology, Key Laboratory of Materials

Chemistry for Energy Conversion and Storage (HUST) of Ministry of Education, School of Chemistry and Chemical Engineering, Huazhong University of Science and Technology (HUST), Wuhan 430074, China

$\S$ These authors contributed equally to this work

*Corresponding Authors: zhanglianbin@hust.edu.cn (L. Z.)

jtzhu@mail.hust.edu.cn (J. Z.)

\section{Table of contents:}

Table S1: Solubility of CTAB in the different solvents used in the work.

Figure S1: SEM and TEM images of the CTAB coated AuNRs $(28 \mathrm{~nm} \times 7.5 \mathrm{~nm})$ synthesized by the seedgrowth method.

Figure S2: TEM images of thiol-terminated polymers regioselective modified AuNRs $(28 \mathrm{~nm} \times 7.5 \mathrm{~nm})$.

Figure S3: UV-vis spectra of CTAB coated and thiol-terminated polymers regioselective modified AuNRs $(28 \mathrm{~nm} \times 7.5 \mathrm{~nm})$.

Figure S4. TEM images and statistical results of silica shell growth on a-c) AuNRs@End-PEO; d-f);AuNRs and g-i)AuNRs@Full-PEO. We counted 100 particles in each sample. 
Figure S5: SEM and TEM images of the deformed and aggregated AuNRs within $72 \mathrm{~h}$ after modification with PEG-SH in cold water $\left(\mathrm{T}<10{ }^{\circ} \mathrm{C}\right)$.

Figure S6: TEM images of the AuNRs after different modification conditions, followed by coordination with CdSe QDs.

Figure S7: TEM images and UV-vis spectra of AuNRs@End-P4VP/Side-PS and its linear assemblies.

Figure S8: SEM images of CTAB coated AuNRs $(66 \mathrm{~nm} \times 15 \mathrm{~nm})$ synthesized by the seed-growth method and AuNRs regionally coated with silica.

Figure S9: SEM images of CTAB coated AuNRs $(110 \mathrm{~nm} \times 30 \mathrm{~nm})$ synthesized by the seed-growth method and AuNRs regionally coated with silica.

Figure S10: TEM images of Au@Ag NPs prepared by $66 \mathrm{~nm} \times 15 \mathrm{~nm}$ and $110 \mathrm{~nm} \times 30 \mathrm{~nm}$ AuNRs@EndPS/Side-P4VP.

Figure S11: UV-vis spectra of CTAB coated and thiol-terminated polymers regioselective modified AuNRs $(66 \mathrm{~nm} \times 15 \mathrm{~nm})$.

Figure S12: UV-vis spectra of CTAB coated and thiol-terminated polymers regioselective modified AuNRs $(110 \mathrm{~nm} \times 30 \mathrm{~nm})$. 
Supporting Figures:

Table S1: Solubility of CTAB in four commonly used solvents. Table S1: Solubility of CTAB in four commonly used solvents.

\begin{tabular}{|c|c|c|c|c|}
\hline Solvents & $\mathrm{H}_{2} \mathrm{O}\left(20^{\circ} \mathrm{C}\right)$ & $\mathrm{H}_{2} \mathrm{O}\left(30^{\circ} \mathrm{C}\right)$ & $\mathrm{THF}\left(25^{\circ} \mathrm{C}\right)$ & $\mathrm{DMF}\left(25^{\circ} \mathrm{C}\right)$ \\
\hline Solubility for CTAB (g/L) & 13 & 96 & 6 & 23 \\
\hline
\end{tabular}



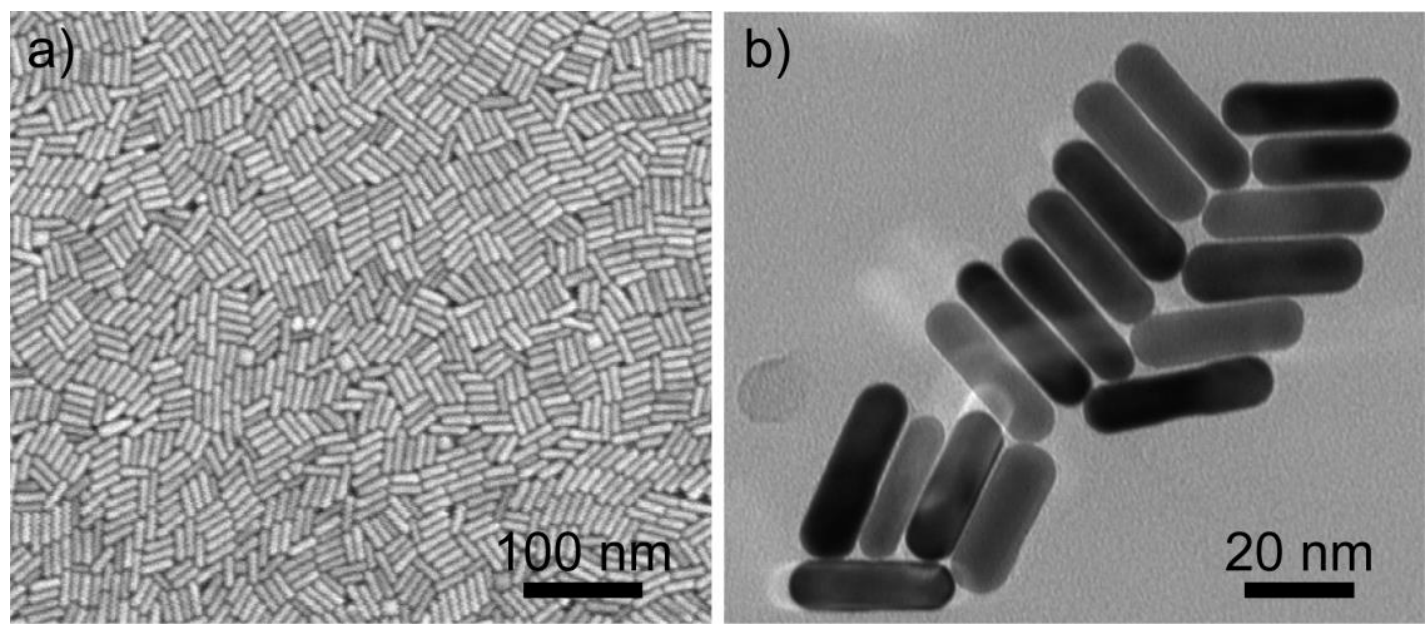

Figure S1. a) SEM image and b) TEM image of CTAB coated AuNRs $(28 \mathrm{~nm} \times 7.5 \mathrm{~nm})$ synthesized by the seed-growth method. 


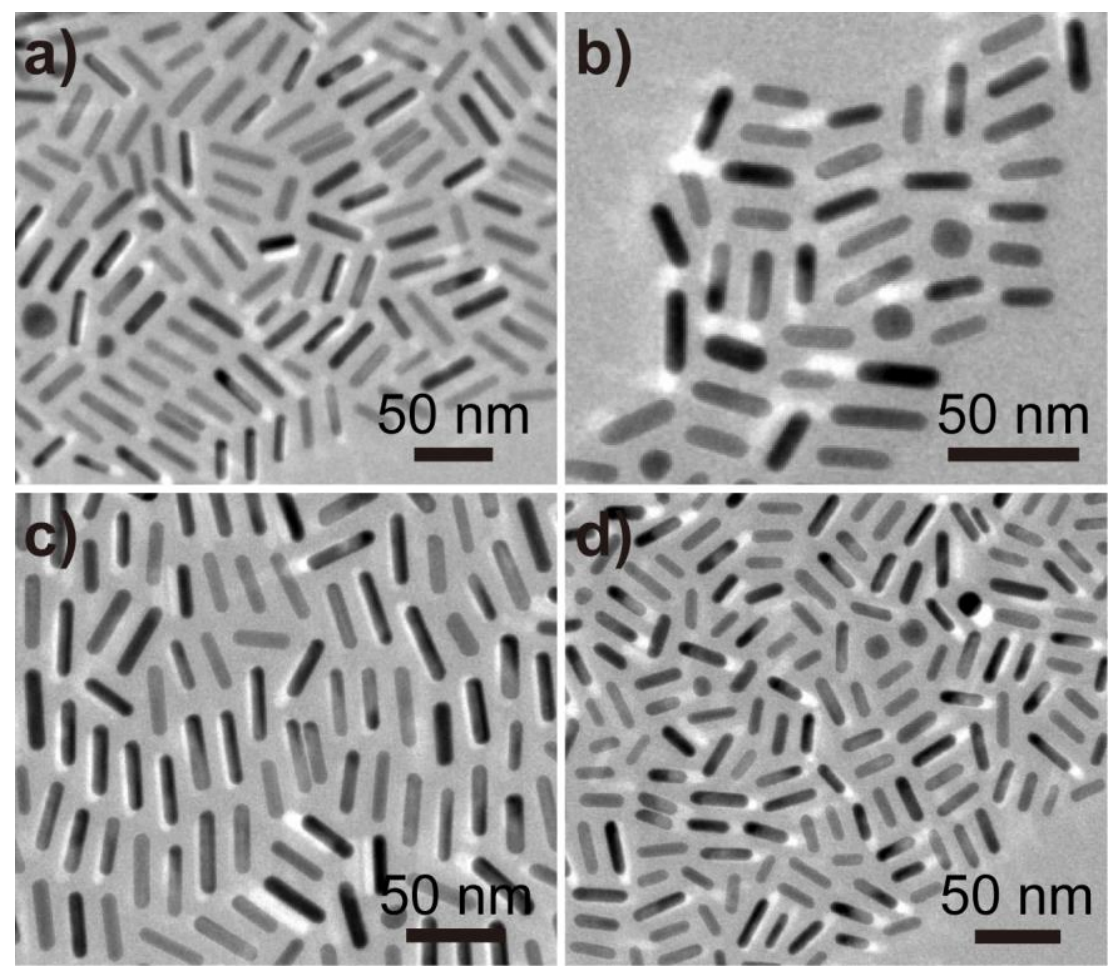

Figure S2. TEM images of a) AuNRs@End-PEO, b) AuNRs@Full-PEO, c) AuNRs@End-PS/Side-P4VP and d)AuNRs@End-P4VP/Side-PS. The length and diameter of the AuNRs is $28 \mathrm{~nm}$ and $7.5 \mathrm{~nm}$, respectively. 


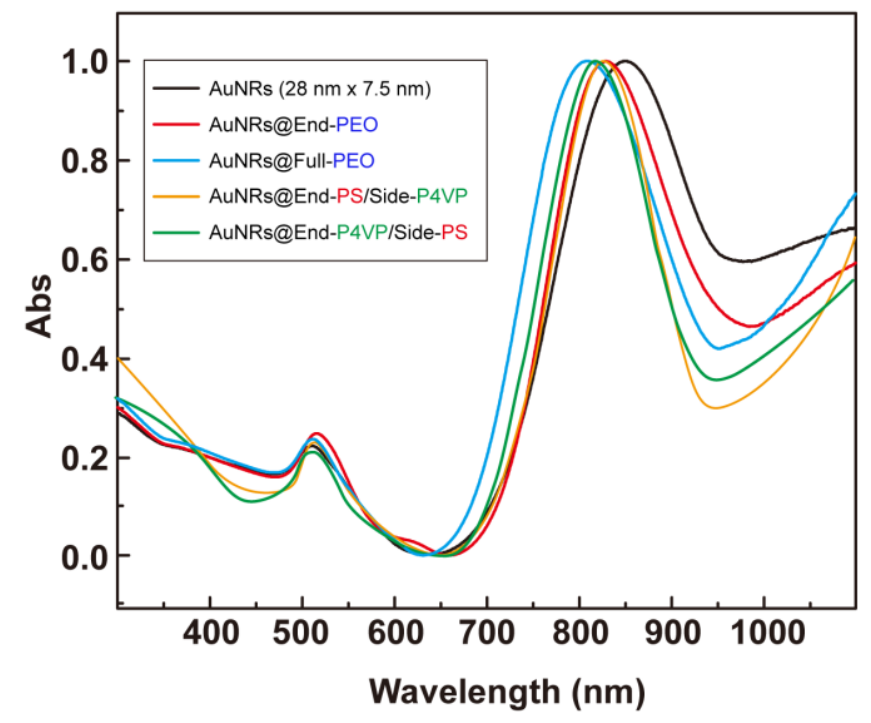

\begin{tabular}{ccc}
\hline & $\begin{array}{c}\text { Longitudinal } \\
\text { LSPR }\end{array}$ & $\begin{array}{c}\text { Transverse } \\
\text { LSPR }\end{array}$ \\
\hline AuNRs (28 nm x 7.5 nm) & $850 \mathrm{~nm}$ & $510 \mathrm{~nm}$ \\
AuNRs@End-PEO & $829 \mathrm{~nm}$ & $515 \mathrm{~nm}$ \\
AuNRs@Full-PEO & $809 \mathrm{~nm}$ & $511 \mathrm{~nm}$ \\
AuNRs@End-PS/Side-P4VP & $827 \mathrm{~nm}$ & $513 \mathrm{~nm}$ \\
AuNRs@End-P4VP/Side-PS & $817 \mathrm{~nm}$ & $512 \mathrm{~nm}$ \\
\hline
\end{tabular}

Figure S3. UV-vis spectra of CTAB coated AuNRs $(28 \mathrm{~nm} \times 7.5 \mathrm{~nm})$ synthesized by the seed-growth method, and AuNRs@End-PEO, AuNRs@Full-PEO,AuNRs@End-PS/Side-P4VP, AuNRs@End-P4VP/Side-PS prepared by the regioselective modification. 

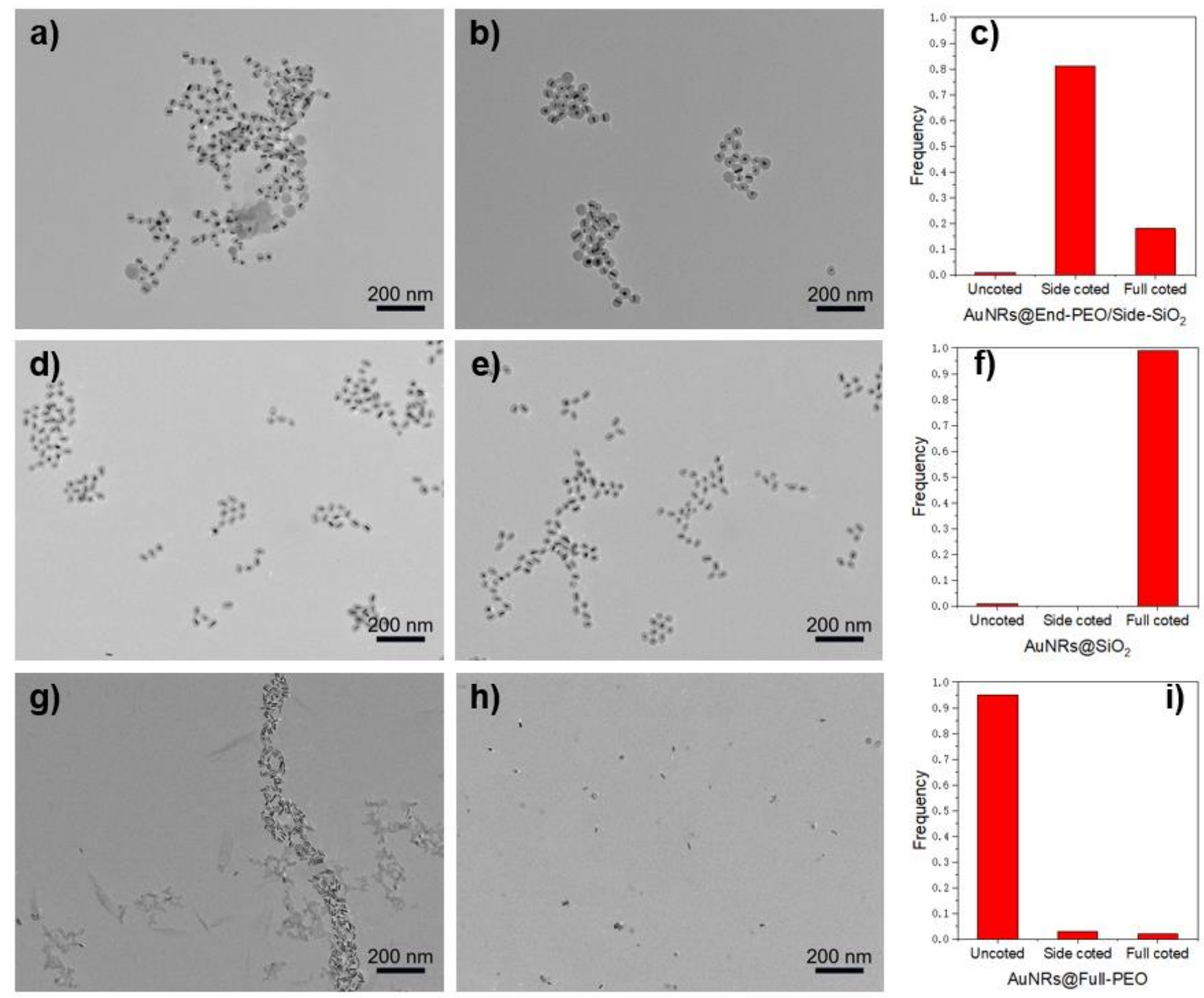

Figure S4. TEM images and statistical results of silica shell growth on a-c) AuNRs@End-PEO; d-f);AuNRs and g-i)AuNRs@Full-PEO. We counted 100 particles in each sample. 

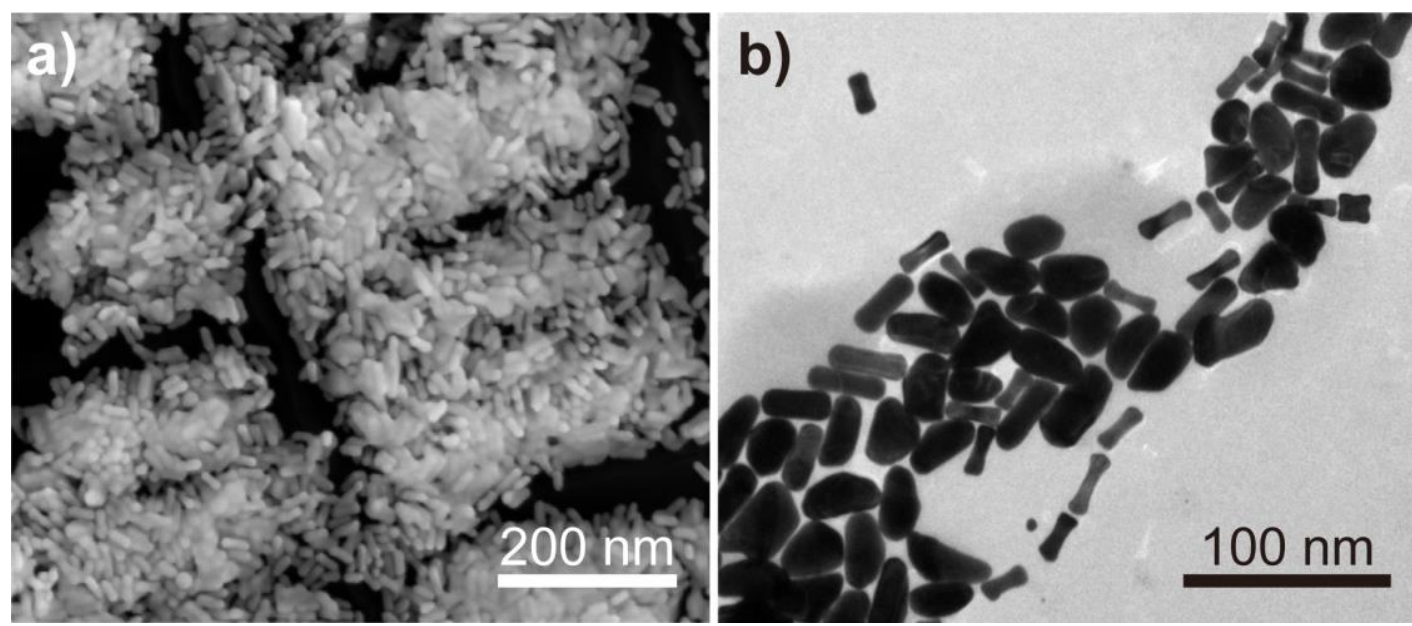

Figure S5. a) SEM image and b) TEM image of the deformed and aggregated AuNRs within $72 \mathrm{~h}$ after modification with PEG-SH in cold water $\left(\mathrm{T}<10^{\circ} \mathrm{C}\right)$. 

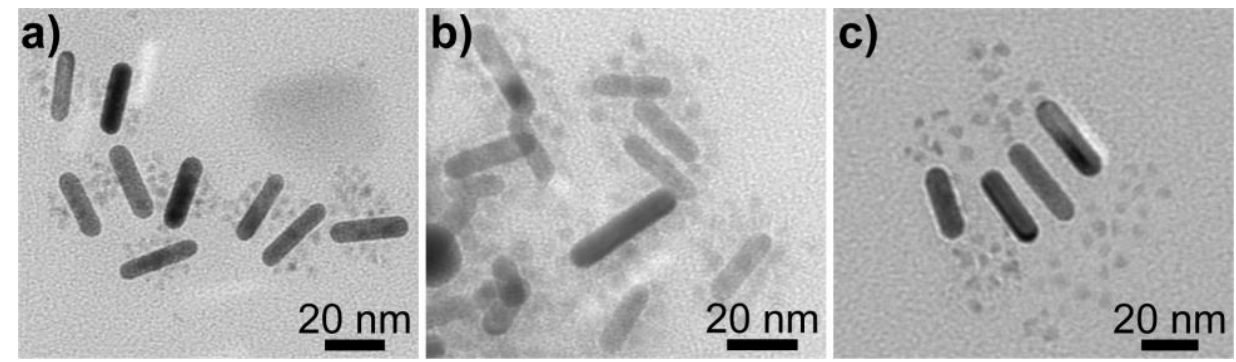

Figure S6. TEM images of the AuNRs after different modification conditions, followed by coordination with CdSe QDs: a)AuNRs@End-PS/Side-P4VP, b) AuNRs@Full-P4VP, and c)AuNRs@End-P4VP/Side-PS. 

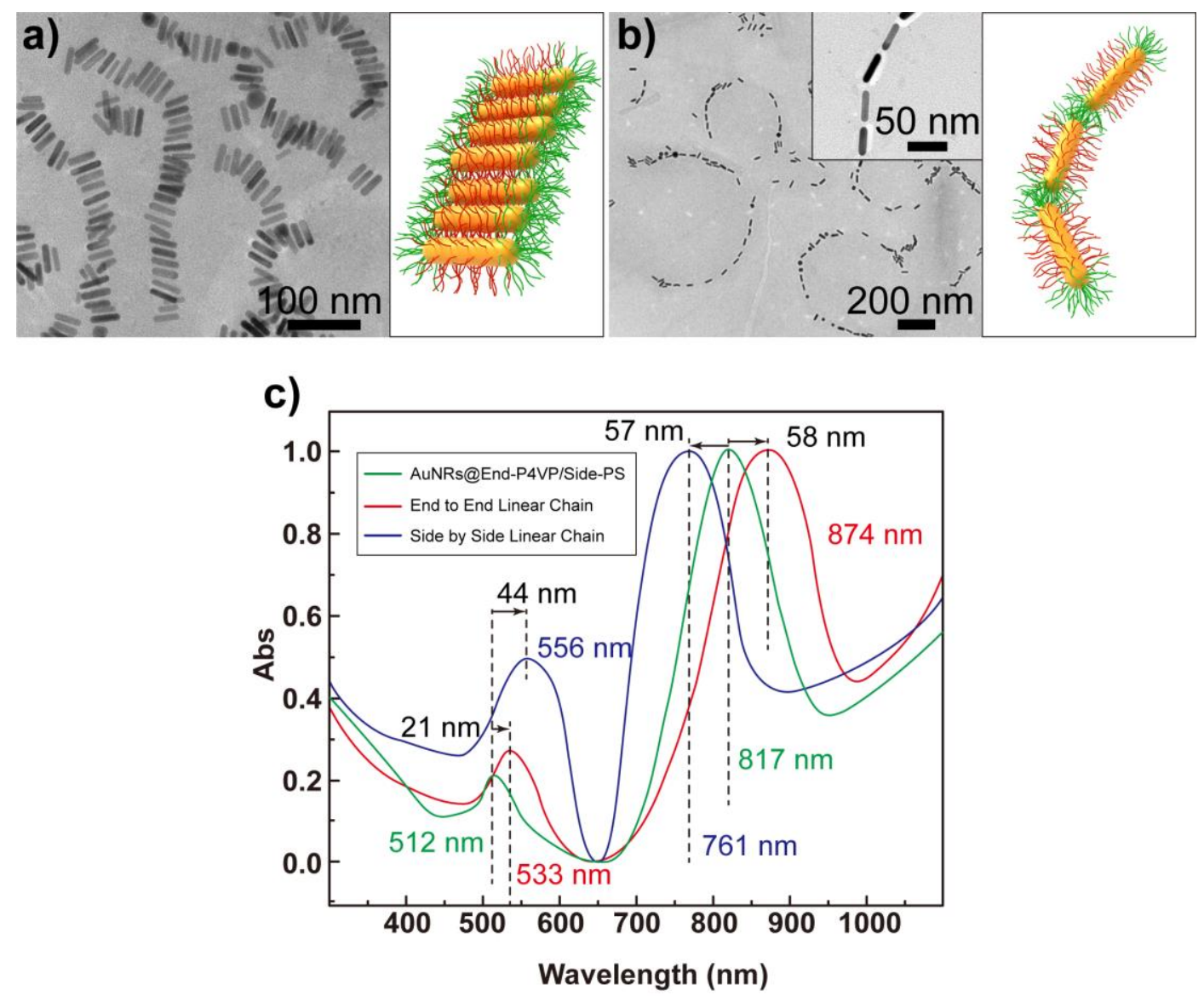

Figure S7. TEM images and corresponding cartoons for self-assembly of AuNRs@End-P4VP/Side-PS in chloroform by adding a) ethanol and b) toluene. Inset in b) is the corresponding high magnification TEM image. c) UV-vis spectra of AuNRs@End-P4VP/Side-PS and its linear assemblies: End to End linear chain and Side by Side linear chain. 

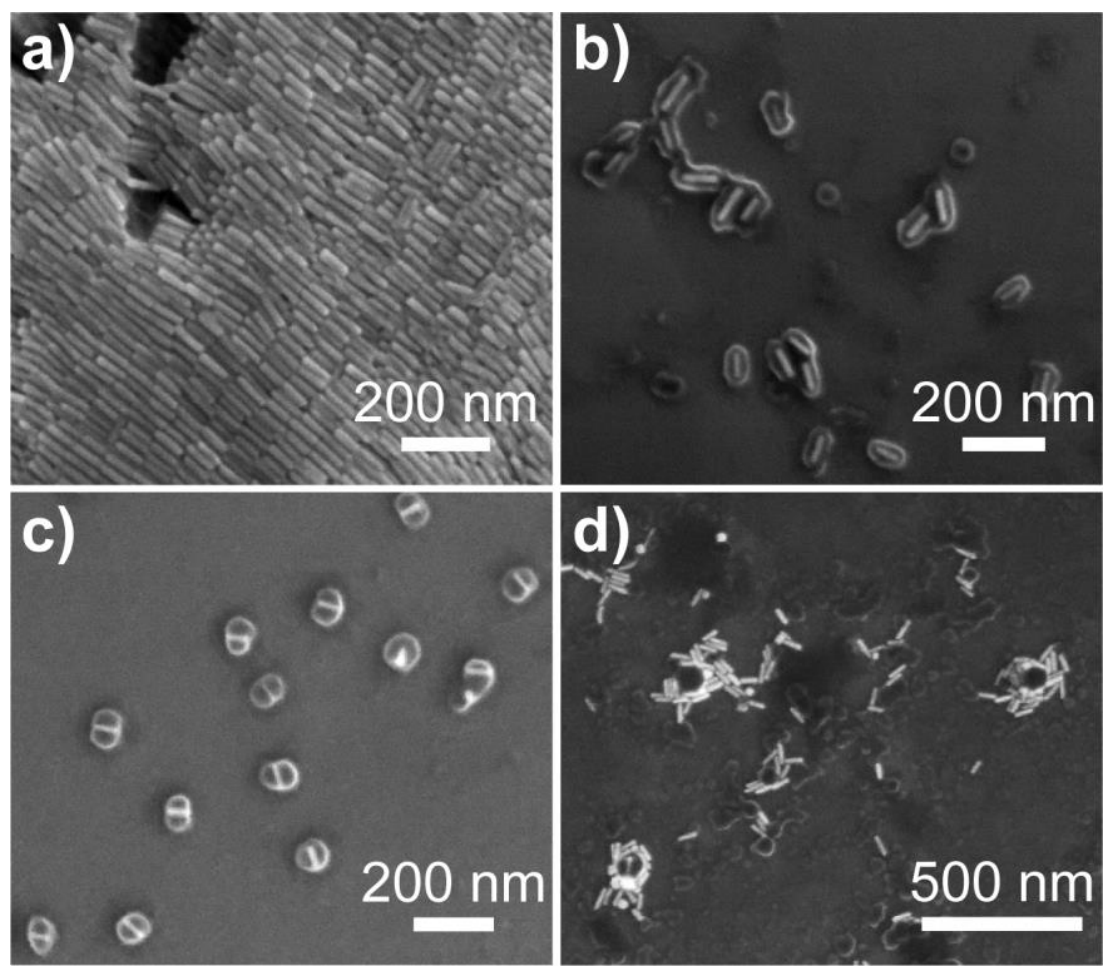

Figure S8. SEM images of a) CTAB coated AuNRs $(66 \mathrm{~nm} \times 15 \mathrm{~nm})$ synthesized by the seed-growth method and AuNRs regionally coated with silica: b) AuNRs, c)AuNRs@End-PEO, and d) AuNRs@Full-PEO. 

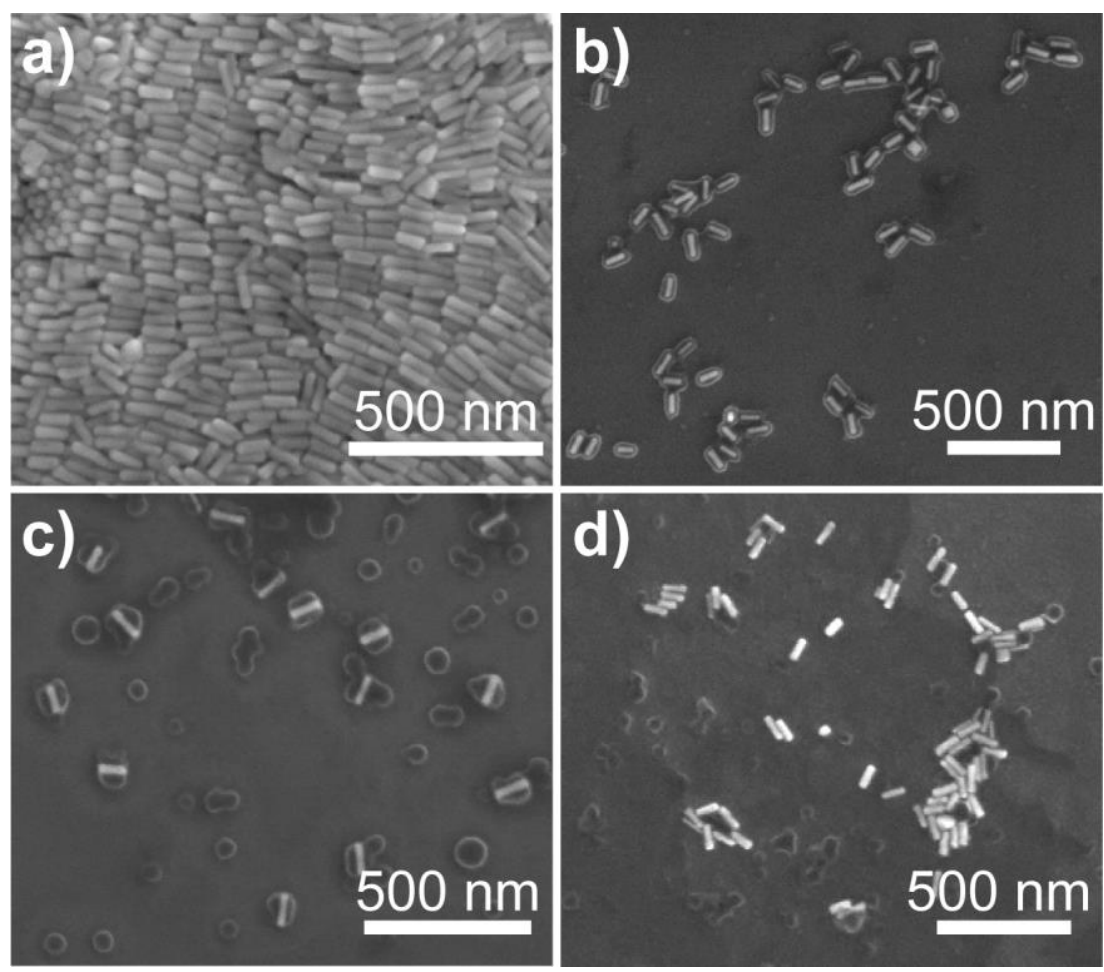

Figure S9. SEM images of a) CTAB coated AuNRs $(110 \mathrm{~nm} \times 30 \mathrm{~nm})$ synthesized by the seed-growth method and AuNRs regionally coated with silica: b) AuNRs, c) AuNRs@End-PEO, and d)AuNRs@Full-PEO. 


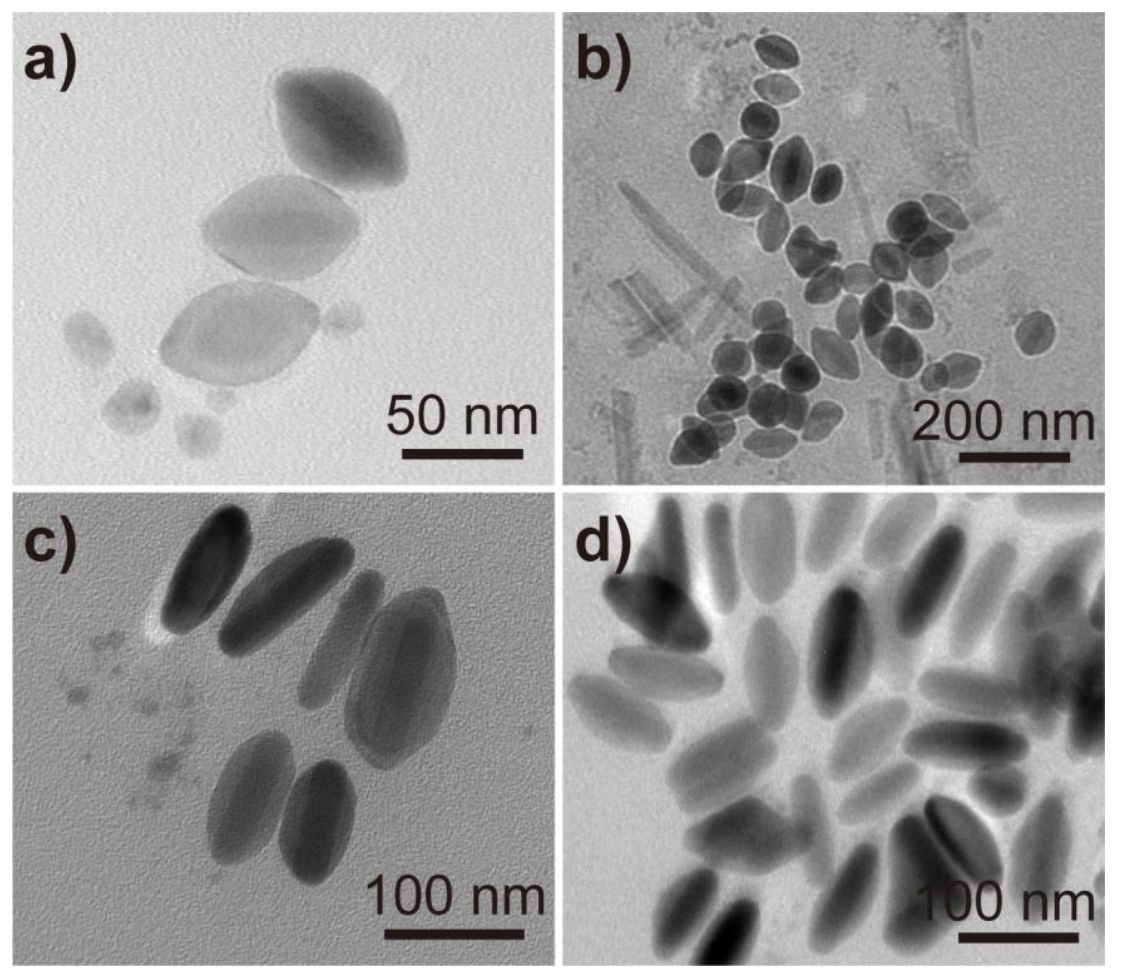

Figure S10. TEM images of Au@Ag NPs prepared by: a, b) 66 nm × 15 nm AuNRs@End-PS/Side-P4VP and c, d) 110 nm × 30 nm AuNRs@End-PS/Side-P4VP. 


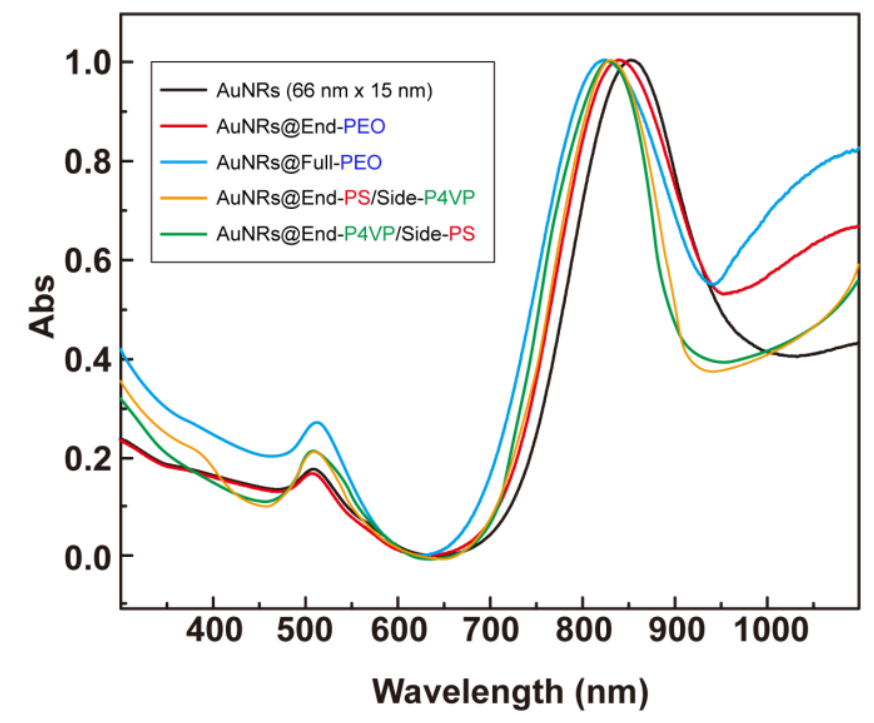

\begin{tabular}{ccc}
\hline & $\begin{array}{c}\text { Longitudinal } \\
\text { LSPR }\end{array}$ & $\begin{array}{c}\text { Transverse } \\
\text { LSPR }\end{array}$ \\
\hline AuNRs $(66 \mathrm{~nm} \times 15 \mathrm{~nm})$ & $853 \mathrm{~nm}$ & $510 \mathrm{~nm}$ \\
AuNRs@End-PEO & $840 \mathrm{~nm}$ & $508 \mathrm{~nm}$ \\
AuNRs@Full-PEO & $825 \mathrm{~nm}$ & $513 \mathrm{~nm}$ \\
AuNRs@End-PS/Side-P4VP & $831 \mathrm{~nm}$ & $511 \mathrm{~nm}$ \\
AuNRs@End-P4VP/Side-PS & $834 \mathrm{~nm}$ & $512 \mathrm{~nm}$ \\
\hline
\end{tabular}

Figure S11. UV-vis spectra of CTAB coated AuNRs $(66 \mathrm{~nm} \times 15 \mathrm{~nm})$ synthesized by the seed-growth method, and AuNRs@End-PEO, AuNRs@Full-PEO,AuNRs@End-PS/Side-P4VP, AuNRs@End-P4VP/Side-PS prepared by the regioselective modification. 


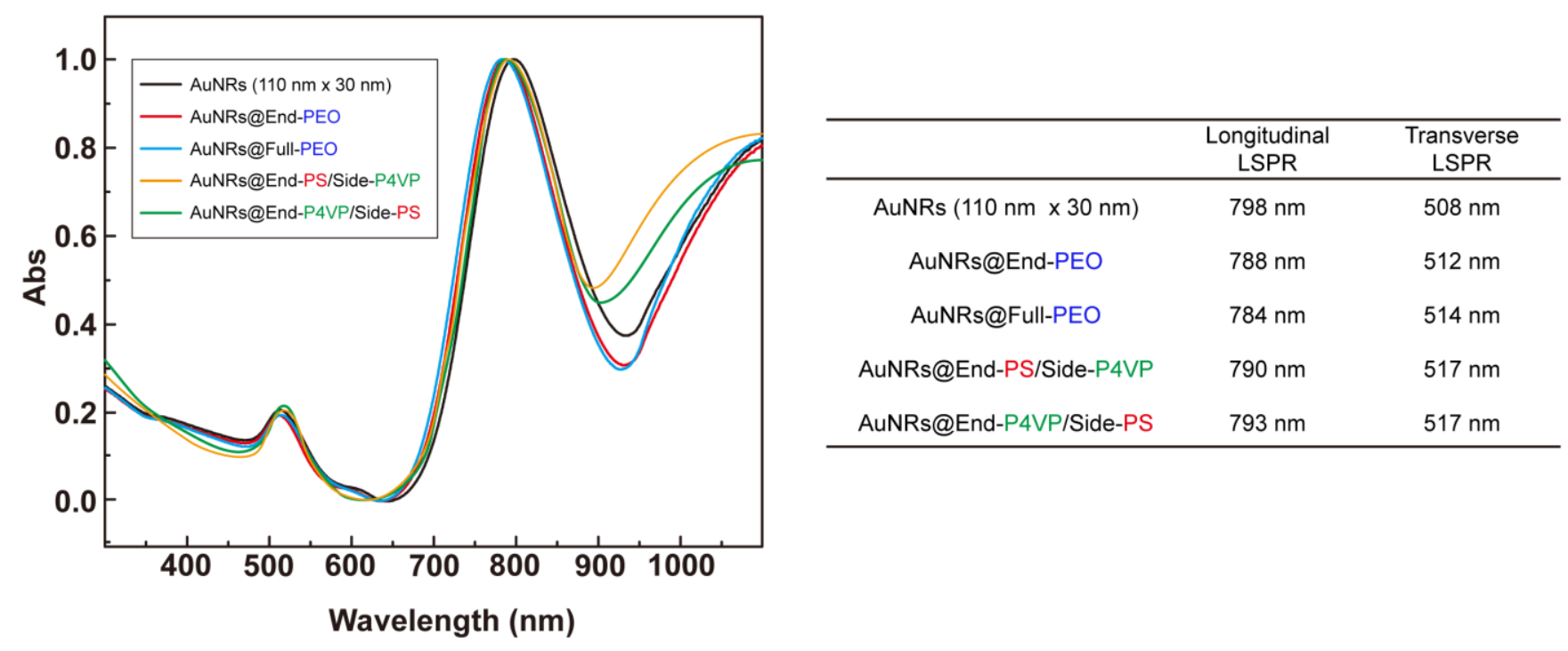

Figure S12. UV-vis spectra of CTAB coated AuNRs $(110 \mathrm{~nm} \times 30 \mathrm{~nm})$ synthesized by the seed-growth method, and AuNRs@End-PEO, AuNRs@Full-PEO,AuNRs@End-PS/Side-P4VP, AuNRs@End-P4VP/Side-PS prepared by the regioselective modification. 